doping in sport, there is an urgent need for increased education among athletes and the general public regarding performance-enhancing substances. This book notably contributes to this education. Based on solid research, it also has the potential to serve as an excellent reference book for any physician, trainer, or health-related professional involved in the care of athletes.

Jeffrey S. Peterson, MD

Palo Alto, CA, USA

\section{Don't Get Eaten: The Dangers of Animals That Charge or Attack}

Dave Smith

Seattle, WA: The Mountaineers Books, 2003

US \$6.95, 93 pages, softcover

\section{Don't Get Bitten-The Dangers of Things That Bite or Sting}

Buck Tilton

Seattle, WA: The Mountaineers Books, 2003

US \$6.95, 95 pages, softcover

The Mountaineers Books has produced 2 volumes in a series dedicated to staying healthy and safe in the outdoors. The first of this series, Don't Get Sick-The Hidden Dangers of Camping and Hiking, by Buck Tilton, MS, and Rick Bennett, PhD, was released last year and was met with favorable reviews (see review by editor Robert L. Norris in Wilderness Environ Med. 2003;14: 151). The new books are both well-written and informative additions to the series.

The goal of Don't Get Eaten, as mentioned in the introduction, is to help the reader "avoid conflicts and confrontations with potentially dangerous North American land mammals." This goal is accomplished in 9 chapters that discuss potential encounters with animals ranging in size from the grizzly to the javelina. Each chapter starts with a hypothetical scenario and goes on to review relevant facts and safety strategies. The author's attempts to dispel myths about animal attacks are particularly welcomed and provide a balanced perspective to the work.

Dedicated to the prevention of bites and stings from dangerous reptiles and insects, Don't Get Bitten is written in a similar format and is equally informative. The potential hazards of dangerous reptiles, spiders, scorpions, and a variety of other insects are discussed clearly and concisely. The brief reviews of bite and sting treatments in each of the 8 chapters are especially relevant to the wilderness medical provider.
In summary, these small books are highly informative and would be of value to anyone with an interest in wilderness medicine. They are enjoyable to read, educational, and at times entertaining. The reader looking for a detailed and referenced review of each species could find the books to be too concise and lacking in specifics. Yet, their small size makes them ideal for outdoor reading and travel, and for their size, these volumes provide an outstanding review of the basics of animal injury, prevention, and treatment.

Thomas J. Nuckton, MD San Francisco, CA, USA

\author{
Iserson's Getting Into a Residency: A Guide for \\ Medical Students, 6th edition \\ Kenneth V. Iserson, MD \\ Tucson, AR: Galen Press, 2003 \\ US \$38.95, 640 pages, softcover
}

This is the sixth edition of Iserson's very popular book geared toward helping medical students focus their energies while in school, with the goal of attaining their desired residency position. Released in 2003, this edition has updates regarding the instatement of the Clinical Skills Exam, as well as updated relevant statistics and charts; however, the core of the information remains very similar to previous editions. As in the past, there is extensive information tailored toward DO students, international medical graduates, women, minorities, and individuals with a variety of other special situations.

Iserson guides the student step-by-step through each of the relevant areas medical students consider as they decide what specialty to pursue and how to secure a position in the residency program that best meets their professional goals and preferences. Included in this process is a chapter that specifically discusses each specialty, the work hours involved, the competitiveness of attaining a residency position, and references for further information. After choosing a specialty, attention turns to securing a residency position. The importance of grades, research experience, and board scores are all addressed in relation to a student's competitiveness for residency. One area that is not explicitly detailed is specific numbers in regard to competitiveness. He discusses the "perfect applicant," but unfortunately includes no discussion of "with this board score and these grades, you will traditionally be competitive for this specialty."

Next, the student is guided through the residency application process, including whom to ask for letters of recommendation and how to draft an outstanding curric- 